\title{
Household energy requirement and value patterns
}

\author{
Kees Vringer $^{\mathrm{a}, *}$, Theo Aalbers ${ }^{\mathrm{a}}$, Kornelis Blok ${ }^{\mathrm{b}}$ \\ ${ }^{a}$ Netherlands Environmental Assessment Agency (MNP), P.O. Box 303, 3720 AH Bilthoven, The Netherlands \\ ${ }^{\mathrm{b}}$ Utrecht University, Heidelberglaan 2, 3584 CS Utrecht, The Netherlands
}

Available online 20 February 2006

\begin{abstract}
For an effective consumer energy policy, it is important to know why some households require more energy than others. The aim of the study described here was to examine whether there is a relationship between the total household energy requirement, on one hand, and value patterns, the motivation to save energy or the problem perception of climate change, on the other. To examine these relationships, we held a consumer survey among 2304 respondent households.

We did not find significant differences in the energy requirement of groups of households with different value patterns, taking into account the differences in the socio-economic situation of households. Only for the 'motivation to save energy' we did find that the least motivated group requires $10 \mathrm{GJ}$ more energy than the average and most motivated groups; this is about $4 \%$ of the total household energy requirement.

This means that a self-regulating energy policy, solely based on the fact that a strategy of internalising environmental responsibility will not be effective in saving energy. There are indications that a social dilemma is one of the reasons why people's consumption patterns do not conform to their value patterns, problem perception or motivation to save energy.
\end{abstract}

(C) 2006 Elsevier Ltd. All rights reserved.

Keywords: Household consumption pattern; Value patterns; Motivation

\section{Introduction}

To achieve a more sustainable energy system in the future, it is important to reduce or limit the energy requirement of society. Energy consumption cannot only be limited or reduced by improving the energy efficiency, but also by changing consumption patterns. The IPCC (2001) mentions change in consumption patterns as a possible response option to the treatment of climate change, but the option of changing consumption patterns is insufficiently exposed. For an efficient consumer energy policy, it is important to know how the energy requirement of consumption patterns is established and why some households require more energy than others.

In overviewing the consumption pattern in the Netherlands, Vringer and Blok (1995) found the net household income to be strongly related to the total (direct plus indirect) energy requirement. A wide range of other

\footnotetext{
${ }^{*}$ Corresponding author. Tel.: + 31302743816 ; fax: + 31302744435 .

E-mail address: kees.vringer@mnp.nl (K. Vringer).
}

studies $^{1}$ also examined the energy requirement for consumption and found relationships between energy requirement and socio-economic characteristics such as income. However, differences in the household energy requirement cannot be solely explained by differences in socio-economic parameters such as income, household size and age. Households in a comparable socio-economic situation vary largely in the total energy requirement (Vringer et al., 1997).

The differences in the total household energy requirement are due to differences in consumer behaviour. There are many studies which use different theories and models to explain (parts of) consumer behaviour (see, for example, Steg and Buijs, 2004; Antonides and van Raaij, 1997). These studies indicate that there are many factors influencing the actual consumer behaviour. One often mentioned factor is formed by people's values (Antonides and van Raaij, 1997; Steg and Buijs, 2004; Nordlund and

\footnotetext{
${ }^{1}$ See e.g. Lenzen (1998); Biesiot and Noorman (1999); Weber and Perrels (2000); Munksgaard et al. (2000); Wier et al. (2001); CarlssonKanyama et al. (2002); Pachauri and Spreng (2002); Lenzen et al. (2004, 2006); Pachauri (2004); Cohen et al. (2005).
} 
Garvill, 2002; Valette-Florence and Jolibert, 1990; Poortinga et al., 2004). Values can be defined as desirable goals that serve as guiding principles in people's lives (Steg and Buijs, 2004). According to Antonides and van Raaij (1997) consumers use products and services (means) to realise desirable goals (values) like ambition, independency, comfort, freedom and pleasure. Valette-Florence and Jolibert (1990) analysed the relation between consumption patterns (measured as the purchasing frequency of 140 consumption categories) and values. They found a weak, but not negligible, influence from values on the consumption pattern, independent from socio-economic characteristics. Nordlund and Garvill (2002) quote many studies in which relationships are confirmed between factors such as value orientation and specific pro-environmental behaviours like recycling and buying ecologically produced products. However, pro-environmental behaviour does not have to be relevant to the overall environmental pressure (see also Gatersleben et al., 2002; Stokes et al., 1994).

The emphasis in this analysis is on the relationship between value patterns and total energy requirement. We chose to examine two other non-socio-economic characteristics as well, which could be expected to influence behaviour more directly than values do. These were: (I) the motivation to save energy and (II) the perception of energy-related societal problems. Motivation is a central concept for consumer behaviour. Antonides and van Raaij (1997) state that motivation activates and maintains certain behaviour; it also determines the direction and strength of this behaviour. So, if consumers are motivated to save energy, it can be expected that the more consumers are motivated, the less energy they will require. If consumers act as they think about societal problems, those who think that energy-related societal problems, such as climate change, are more important than other problems can be expected to use less energy.

The aim of this study is to examine whether there is a relationship between, on the one hand, the total household energy requirement and, on the other, value patterns, the motivation to save energy or the perception of energyrelated societal problems.

In this paper, we first describe how we determined the value patterns of consumers and the household energy requirement. Next, we examine the relationship between these, taking into account the socio-economic situation of the households. Finally, we explore the influence of the perception of energy-related societal problems and the motivation to save energy on the total household energy requirement.

\section{The consumer survey}

To examine the relationship between the total household energy requirement, on one hand, and value patterns and the motivation to save energy or the perception of energy-related societal problems, on the other, we used consumer-specific information of 2304 respondents from the consumer survey (TNS-NIPO, 2003). The respondents filled in five different questionnaires; one for value patterns, two for the consumption patterns, one for their view on societal problems and one for the "motivation to save energy'. ${ }^{2}$ Not all 2304 respondents were asked to answer all five questionnaires. There were 2304 respondents who answered the questionnaires on value patterns and both consumption pattern questionnaires. Of these 2304 respondents, 1272 answered the questionnaire about the societal problem perception too and 935 answered the motivation questionnaire too.

To minimise the initial non-response we used a panel from the Dutch Institute for Public Opinion and Market Research (TNS-NIPO) for the consumer survey. TNSNIPO took a random representative sample for Dutch households from a pool of about 80,000 respondents who were invited by TNS-NIPO to register for the panel. The response to our questionnaires was about $80 \%$. After collecting the data we weighted the respondents according to net household income, size of the household, age and education of the breadwinner. ${ }^{3}$

\section{Determination of value patterns}

The value patterns of consumers are determined according to the WIN-model ${ }^{4}$ from TNS-NIPO (Hessing-Couvret and Reuling, 2002). The WIN-model is based on the value system of Rokeach (1973) and the work of Schwartz and Bilsky (1987).

According to Rokeach, in a value system values are ordered in priority of importance. A value is an enduring belief that a specific mode of conduct or end-state of existence is personally or socially preferable to an opposite or converse mode of conduct or end-state of existence. Rokeach distinguishes 36 values - all socially desirableinto two groups. One group contains 18 instrumental values (modes of conduct) and the other contains 18 terminal values (end states of existence) (see Table 1).

Schwartz and Bilsky (1987) found that seven motivational domains, taken from the literature, are organised relevant to one another and can be projected in a value space. Each domain contains a number of accompanying values belonging together (e.g. the motivational domain, 'security', includes values of inner harmony, family security, national security and a world at peace).

For this study, each respondent had to rank the two lists according to how important the values are for him/herself. The value space was transformed to two dimensions with the help of a principal component analysis (PRINCALS). Finally, Hessing-Couvret and Reuling (2002) made a cluster analysis for the respondents in the value space.

\footnotetext{
${ }^{2}$ The motivation questions were borrowed from an ECN questionnaire (see Kets et al., 2003).

${ }^{3}$ In this study, the breadwinner is the person in the household with the highest personal income

${ }^{4}$ WIN $=$ Values in the Netherlands (Waarden In Nederland).
} 
Table 1

The two lists of 18 values each, according to Rokeach (1973)

\begin{tabular}{ll}
\hline $\begin{array}{l}\text { Instrumental values } \\
\text { (desired modes of conduct) }\end{array}$ & $\begin{array}{l}\text { Terminal values } \\
\text { (desired end-states of existence) }\end{array}$ \\
\hline 1. Ambitious & 1. A comfortable life \\
2. Broadminded & 2. A sense of accomplishment \\
3. Capable & 3. A world at peace \\
4. Cheerful & 4. A world of beauty \\
5. Clean & 5. An exciting life \\
6. Courageous & 6. Equality \\
7. Forgiving & 7. Family security \\
8. Helpful & 8. Freedom \\
9. Honest & 9. Happiness \\
10. Imaginative & 10. Inner harmony \\
11. Independent & 11. Mature love \\
12. Intellectual & 12. National security \\
13. Logical & 13. Pleasure \\
14. Loving & 14. Salvation \\
15. Obedient & 15. Self-respect \\
16. Polite & 16. Social recognition \\
17. Responsible & 17. True friendship \\
18. Self-controlled & 18. Wisdom \\
\hline
\end{tabular}

One is with the instrumental values and one is with the terminal values.

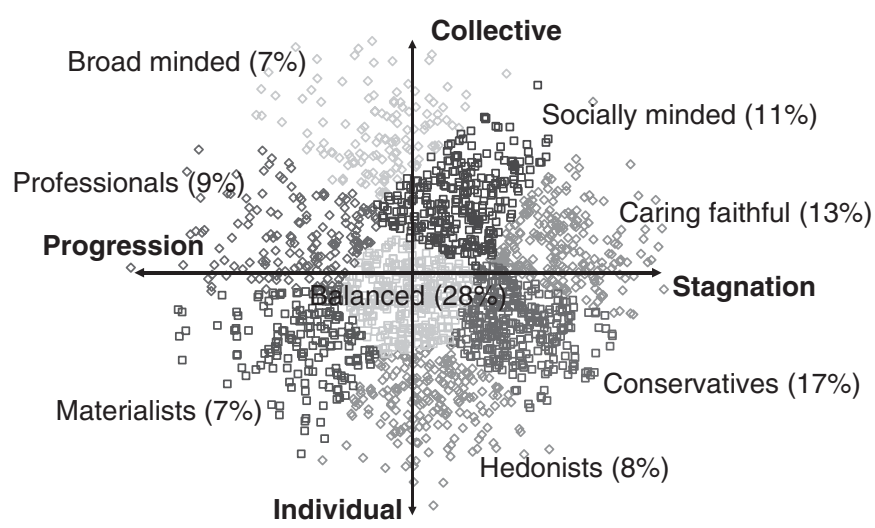

Fig. 1. The eight value groups positioned in the value space, with two important axes (Hessing-Couvret and Reuling, 2002). The percentages reflect the size of the groups in the Dutch population, each tiny square representing one person.

They forced an eight-cluster solution and gave names to the clusters, based on the value occurring in each group and other known aspects (see Fig. 1). In other words, the names mentioned in Fig. 1 are not based on the perception of the respondents but refer to names taken from HessingCouvret and Reuling (2002).

Fig. 1 shows the eight value groups in a two-dimensional space. One axis indicates a collective-individual dimension. Expectedly, consumers with a more individualistic value pattern like the Hedonists, Conservatives and Materialists are less focused on such societal problems as climate change than the consumers with a more collective value pattern such as the broad-minded and socially minded. This makes it interesting to compare value groups of consumers with respect to their energy requirements.

\section{Determination of the energy requirement}

If the influence of value patterns, the perception of energy-related societal problems or the motivation to save energy on the total household energy requirement is to be explored, the actual total consumption pattern of a household and the accompanying energy requirement will have to be determined. We wanted to compare the actual energy consumption of a household with a reference; this is the average for households in the same socio-economic circumstances (see "the estimation of the standard consumption pattern'). The determination of the actual consumption pattern and the calculation of the reference energy requirements are described below.

\subsection{Determining the actual consumption pattern}

The emphasis of the information provided by the respondents of the consumer survey is on the consumption categories demanding a considerable amount of energy or money. To avoid the conversion from monetary into physical terms, we collected the information mainly in physical terms. Because the expenditure on durable consumer goods (e.g. cars) for individual consumers may peak in the survey year, we requested information on purchase and possession of these goods. Detailed information was requested on six groups of consumption categories: natural gas, electricity, transport, holidays abroad, the dwelling and food.

To determine the actual consumption pattern, we first made a standard consumption pattern and the accompanying energy requirement. This standard consumption pattern is solely based on the socio-economic situation of the households. We did this using the Household Expenditure Survey (CBS, 2002a). With the help of the detailed responses to our own survey, we adapted this standard consumption pattern to get the actual household energy requirement for the six groups of consumption categories using a method described below. These six groups of consumption categories collectively make up about $75 \%$ of the total energy requirement. Finally, the expenditures and accompanying energy requirement for the remaining consumption categories were established.

\subsubsection{The estimation of the standard consumption pattern}

The estimation of the standard consumption pattern and the accompanying energy requirement is based solely on the socio-economic situation of the households. To each household of the consumer survey, we coupled the average expenditure and the accompanying energy requirement of 350 consumption categories of the 10 most similar households from the household expenditure survey of 2000 (CBS, 2002a). ${ }^{5}$ To find the 10 most similar households from the

\footnotetext{
${ }^{5}$ The household expenditure survey contains the expenditure of 2395 representative households in the Netherlands in 2000, divided into about 350 consumption categories. Vringer and Blok (1995) gave a detailed
} 
expenditure survey, we characterised each household by a vector. We chose the 10 households from the expenditure survey, in which the difference in vector length between their vector and the vector of the household from the consumer survey is the smallest. ${ }^{6}$ We based the vector on the socio-economic parameters that 'explain' most of the variance in the energy requirement for most consumption domains, ${ }^{7}$ using a regression tree analysis. ${ }^{8}$ About $65 \%$ of the variance in the energy requirement can be explained by all the socio-economic characteristics available in the expenditure survey. The net income is, by far, the most important factor in explaining the variance of the total household energy requirement (about 60\%). We selected net income, age of the breadwinner, highest education of the breadwinner and household size, ${ }^{9}$ normalising these four dimensions. ${ }^{10} \mathrm{We}$ chose the weighting factors for the socio-economic variables of the vector to reflect the relative proportions of the separately 'explained' variance of the total energy requirement. The separately explained variances of the total energy requirement of net household income, household size, age and education are $62 \%, 36 \%$, $15 \%$ and $7 \%$, respectively. The difference in vector length between the vectors of two households is then calculated according to

$$
\begin{aligned}
V^{2}= & a\left(I_{h e s}-I_{c s}\right)^{2}+b\left(\text { Age }_{h e s}-A g e_{c s}\right)^{2} \\
& +c\left(H H s_{h e s}-H H s_{c s}\right)^{2}+d\left(E d_{h e s}-E d_{c s}\right)^{2},
\end{aligned}
$$

where $V$ is the weighted difference between the vectors of two households, $I$ the normalised net household income,

\section{(footnote continued)}

description of the survey. The figures of the household expenditure survey figures were adjusted for transport and direct energy requirement according to Vringer et al. (2001) and MONIT (2003). The energy requirement for each consumption category is calculated according to the method described in Vringer and Blok (1995) by using energy intensities for 1996 given by Kok et al. (2001). The energy intensities are indexed to 2000 on the basis of consumer price indexes according to CBS (2002b) and Erkens (2002).

${ }^{6}$ In this analysis, we chose 10 similar households to calculate the reference consumption pattern. We also made calculations for 5, 25 and 50 similar households. The results were comparable.

${ }^{7}$ These are the nine domains used by Vringer et al. (2001), i.e. food, dwelling, housing, clothing, personal care, leisure outdoors, leisure indoors, holidays and labour. Note that the domains do not only consist of the products themselves, but also the required transport of these products from the shop to the dwelling, and the direct energy (natural gas, electricity) required to use these products.

${ }^{8}$ In a regression tree analysis, the variance in the dependent variable (here, the energy requirement) is minimised by breaking up the data, using every possible binary split on every independent variable (here, many socio-economic parameters). The algorithm split the data into two parts by minimising the sum of the squared deviations from the mean in the separate parts. This splitting or partitioning is then applied to each of the new branches. We used a regression-tree model from S-PLUS.

${ }^{9}$ For the consumption survey, comprising $52 \%$ men and $48 \%$ women, we took the breadwinner or his/her partner. Their ages were strongly correlated $\left(R^{2}=0.84\right)$.

${ }^{10}$ Each dimension is normalised by subtracting the average value from the actual value, and dividing this difference by the standard deviation of the value.
$E d$ the normalised highest education of the breadwinner, $H H s$ the normalised household size, in number of persons, Age the normalised age of the breadwinner, hes the household expenditure survey, cs the consumer survey and $a, b, c, d$ are weighting factors of $0.51,0.12,0.30$ and 0.06 , respectively.

The average consumption pattern according to the expenditure survey and the average standard consumption pattern calculated here are quite comparable. The differences between the expenditure survey of 2000 and the standard consumption pattern calculated here vary per consumption domain from $2 \%$ to $14 \%$ of the expenditures and from $0 \%$ to $14 \%$ of the energy requirement.

\subsubsection{Natural gas and electricity}

We asked the respondents about their payments to the energy companies, and which additional services were included in these payments, e.g. water, cable television and Internet. Next, we asked the respondents how much $\mathrm{kWh}$ electricity and $\mathrm{m}^{3}$ natural gas they had used in the past year, based on their most recent annual bill.

- Expenditures: We based the annual expenditure on the monthly payments to the energy companies as reported by the respondents. ${ }^{11}$ If applicable, we subtracted the expenditures on additional services, based on average expenditures according to CBS (2002a) and CASEMA (2003). To split the combined bills into the shares for electricity and natural gas $(85 \%$ of the households has a combined bill), we took the proportion of natural gas and electricity used as reported by the respondents. If the natural gas and electricity consumption in $\mathrm{m}^{3}$ and $\mathrm{kWh}$ was unknown, we took the proportions of the standard consumption pattern.

- Energy use: Half the respondents knew their use of natural gas and electricity in $\mathrm{m}^{3}$ and $\mathrm{kWh}$. For all other respondents for whom the physical use of gas, heating or electricity use was unknown, ${ }^{12}$ we established the energy requirement by using the expenditures on electricity and natural gas, minus the costs for the grid connections plus the eco-tax rebates (van Maanen, 2003). The resulting expenditures and the $\mathrm{kWh}$ electricity and $\mathrm{m}^{3}$ natural gas used were multiplied by the energy intensities (see Kok et al., 2001).

\subsubsection{Transport}

We asked the respondents how many cars they had, the type and age of the car and the annual distance travelled with this car for private use. We also asked how many kilometres they travelled between home and work and leisure and how they travelled for these purposes.

\footnotetext{
${ }^{11}$ About $20 \%$ of the respondents had to make an estimation.

${ }^{12}$ The energy requirement of households that use district heating or a central heating boiler (about $9 \%$ ) could not be established unambiguously either.
} 
- Expenditures: We estimated the depreciation and maintenance costs of the car by taking into account its age, catalogue value and type. ${ }^{13}$ We based the insurance costs and ownership tax of the car on the average insurance costs, according to the type of the car (ANWB, 2003; Belastingdienst, 2003; Consumentenbond, 2003). The calculated fuel costs were based on the reported or estimated fuel use per km, type of fuel, the reported number of kilometres driven and the fuel price (CBS, 2003). The expenditures on train and/or bus were estimated using average distance travelled, the frequency and the bus and train fares (NS, 2003; GVU, 2003).

- Energy use: The energy requirement for fuel was calculated with the energy requirement per litre according to Wilting et al. (1999). The energy requirement for public transport, car maintenance and depreciation was calculated by using energy intensities from Kok et al. (2001).

\subsubsection{Holidays abroad}

We asked respondents who travelled abroad in the past year to tell us for each destination how they travelled and with how many persons. We also asked the kind and comfort level of the accommodation. We asked for detailed descriptions about the three longest holidays, assuming that the fourth and subsequent holidays would be equal to the third, or shortest, holiday.

- Expenditures: The expenditures on holidays abroad were based on the number of participating household members, duration, type and comfort level of the accommodation, mode of transport and destination (country or region). Fares for train, plane and boat were collected from Internet sites of several tour operators. Information on prices for accommodation as found on the Internet and brochures vary largely. Based on information from Aalbers (2004), we assumed an average price of 8 euro per person per night for a camping, 50 euro per night for a double room in a hotel and 450 euro per week for an apartment or holiday home. We indexed the (Dutch) prices for the different country regions with the Big-Mac index (The Economist, 2004) for luxury class accommodation. ${ }^{14}$

- Energy use: The energy requirement for transport between home and final destination for holidays abroad was based on the energy requirement per kilometre (de Paauw, 1995; Essen et al., 2003). Where the car was used for holiday transport, we took the energy requirement per kilometre of the largest car. Extra fuel was taken

\footnotetext{
${ }^{13}$ For lease cars, we took only the depreciation that could be assigned to the private use of the car.

${ }^{14} \mathrm{We}$ asked the respondents about the level of luxury of their accommodation. We assumed price differences from very simple, no star $(-30 \%)$, simple, 1 star $(-10 \%)$, average, 2 stars $(0 \%)$, luxury, 3 stars $(+20 \%)$ to very luxury, 4 or more stars $(+40 \%)$.
}

into account for mobile home use. The energy requirement for the accommodation is based on the energy requirement per person/accommodation per night (see de Paauw, 1995).

\subsubsection{Dwelling}

We asked the respondents which type of dwelling they lived in and to tell us about the rent and several physical aspects of their dwelling (e.g. surface area of the livingroom and number of rooms).

- Expenditures: About $40 \%$ of the respondents rent their dwelling, of which $88 \%$ knew their rent and $11 \%$ estimated it. About $1 \%$ did not really know how much rent they paid. For these respondents, we took the expenditure and energy requirement according to the standard consumption pattern. To make a fair comparison with owner-occupants we calculated the rental value equivalent to the rent. To estimate the rental value for the remaining $60 \%$ owner-occupants, we used a model from Statistics Netherlands (CBS) to calculate the gross economic rental value (Sierman, 2003). To calculate the rental value of the dwelling, the model takes the type, age, size, region and a number of facilities like bath and type of heating into account.

- Energy use: The calculation of the energy requirement was based on the size and type of dwelling, according to the method used by Vringer and Blok (1993). We took into account the re-calculations made by Kok et al. (2001).

\subsubsection{Food}

We asked the respondents about their food consumption, for example, how often they cooked a warm meal at home, what type of meal they ate, what kind of meat they ate and how often they consumed fresh and/or conserved vegetables, and fruit and dairy products. This information is used to change the ratio between the food consumption categories, available from the standard consumption pattern. For example, the number of times in a week a household enjoys dessert is assumed to affect the expenditure on custard and porridge. By calculating the expenditure and energy requirement on custard and porridge, we took into account the frequency of eating a dessert. If a household consumes more desserts than average, the expenditure on custard and porridge is raised proportionally. The average expenditure on custard and porridge for all households is kept unchanged. Table 2 shows which information is known, and which consumption categories this information is assumed to affect. More than $50 \%$ of the average expenditure on food is affected in this way.

\subsubsection{Determining the actual consumption pattern}

To establish the actual energy requirement of the actual consumption pattern, we took the estimated standard consumption pattern. We replaced the estimated expenditures and accompanying energy requirements of the six 
Table 2

Information from the consumer survey and the consumption categories affected

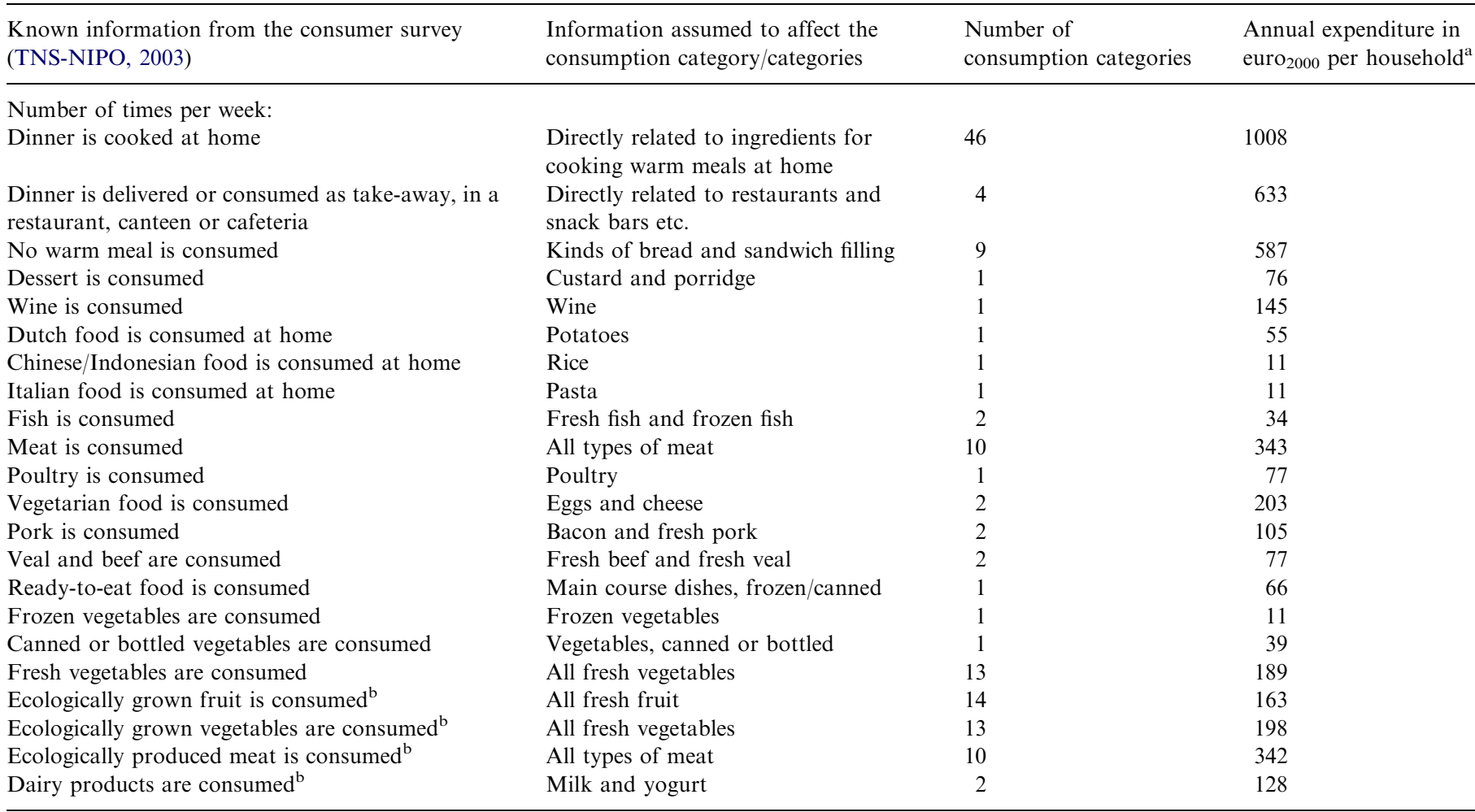

\footnotetext{
${ }^{a}$ According to the standard consumption pattern.

${ }^{\mathrm{b}}$ Only price differences between regular and ecological products are taken into account. We assume that ecologically grown vegetables are $25 \%$ more expensive, fruit $30 \%$ more expensive and meat $50 \%$ more expensive than traditionally grown vegetables, fruit and meat.
}

groups of consumption categories by the expenditures and accompanying energy requirement for the six categories, as calculated above. This results in the actual consumption pattern. This replacement resulted in an average rise in the total expenditure of about $5 \% .{ }^{15}$ For each respondent, we adjusted the expenditures and energy requirement for the remaining categories by multiplying the estimated expenditures and energy requirements for the remaining consumption categories by a factor to meet the initial expenditure plus the average rise of $5 \% .{ }^{16}$ On average, about $60 \%$ of all expenditures and $75 \%$ of the total household energy requirement is based on mainly physical information from the consumer survey.

\subsection{Calculating a reference energy requirement}

To compare the energy requirement of a household with other households having the same socio-economic characteristics, we calculated a reference energy requirement.

\footnotetext{
${ }^{15}$ Possible causes of this average rise are the high price rise for natural gas and electricity between 2000 (expenditure survey) and 2003 (the year of the consumption survey) and underestimations of the expenditures for these six categories according to the expenditure survey or overestimations according to the consumer survey.

${ }^{16}$ Taking into account the dependency of the average rise with the net income.
}

We based the reference energy requirement of a household on the socio-economic situation only. This reference energy requirement is chosen as, in most cases, the socio-economic situation cannot be easily changed by consumers themselves. We calculated the reference energy requirement using a multiple regression analysis. The four socioeconomic variables which 'explain' most of the variance in the energy requirement (see above) are taken as independent variables. ${ }^{17}$ The reference energy requirement can then be calculated according to

$E_{r e f}=C+(a * I)+(b * H H s)+(d * A g e)+(e * E d)$,

where $C$ is the constant, $E_{r e f}$ the reference energy requirement, $I$ the net household income in $€, H H s$ the household size, in number of persons, Age the age of the breadwinner, $E d$ the highest education of the breadwinner, in education level and $a, b, d, e$ are parameters, depending on the reference energy requirement.

To calculate a reference energy requirement for the six groups of consumption categories and the total energy

\footnotetext{
${ }^{17}$ Wier et al. (2001) found that power functions with elasticity coefficients describe better the dependence of the energy requirement on income than a linear function. However, adding an elasticity coefficient in the equation did not improve the models in this study. For calculating the reference energy requirement we chose for the most simple equation, so elasticity coefficients are left out in the equation.
} 
Table 3

The factors resulting from the stepwise linear regression analyses required for Eq. (2) to calculate the reference energy requirements and the explained variance for each regression analysis $(p<0.05, \mathrm{~ns}=$ not a significant contribution in Eq. (2))

\begin{tabular}{|c|c|c|c|c|c|c|}
\hline \multirow[t]{2}{*}{ Reference energy requirement for } & \multirow[t]{2}{*}{ Constant $C$} & \multicolumn{4}{|c|}{ Factors } & \multirow[t]{2}{*}{ Explained variance } \\
\hline & & a & $\mathrm{b}$ & $\mathrm{d}$ & $\mathrm{e}$ & \\
\hline Natural gas & 2007 & 0.32 & 4882 & 507 & ns & 0.11 \\
\hline Electricity & 10727 & 0.19 & 4682 & 100 & -462 & 0.23 \\
\hline Transport & 57671 & 0.90 & 3489 & -556 & ns & 0.10 \\
\hline Holidays abroad & -4139 & 0.72 & ns & ns & 1703 & 0.09 \\
\hline Dwelling & 4244 & 0.05 & 624 & 35 & 114 & 0.18 \\
\hline Food & -7775 & 0.71 & 2412 & 159 & ns & 0.56 \\
\hline Remaining consumption categories & 16921 & 2.41 & -3081 & ns & ns & 0.59 \\
\hline Total & 46313 & 5.75 & 14853 & 471 & ns & 0.62 \\
\hline
\end{tabular}

requirement, we carried out stepwise regression analyses. The results of these analyses are presented in Table 3.

The explained variance of the total energy requirement is about $62 \%$, comparable with the explained variance of the household expenditure survey of 2000 (CBS, 2002a). The explained variance is relatively small for natural gas, electricity, transport, holidays abroad and dwelling.

\section{Energy requirement and value patterns, motivation and problem perception}

Next, we examine the differences in the energy requirement, which can be related to the values of consumers, their problem perception of energy-related societal problems and their motivation to save energy. To examine the difference in energy requirement, resulting from differences in the perception of energy-related societal problems, we took the problem perception of climate change. Each comparison was corrected for the socio-economic situation of the households.

\subsection{Energy requirement and value patterns}

The value groups with a more individually oriented value pattern, e.g. the Hedonists, Conservatives and Materialists, are expected to use more energy, considering their socioeconomic situation. Fig. 2 shows the average energy requirement for all eight value groups, including the standard error of the mean. Two energy requirements are given for each value group: (I) the reference energy requirement, which can be expected in view of the average socio-economic situation of the group of households and (II) the energy requirement due to the actual consumption pattern.

The differences between the total reference energy requirement and the total actual energy requirement are small; about $0-5 \mathrm{GJ}(0-2 \%$ of the total energy requirement). To examine the significance of the differences between the reference energy requirement and the actual energy requirement, we calculated, for each respondent, the difference between the actual and reference energy requirement $(\Delta E)$. Fig. 3 shows for the total energy requirement the average difference for each value group, including the standard error of the mean. A one-way ANOVA analysis ${ }^{18}$ shows that the $\mathrm{H} 0$-hypothesis, ' $\Delta E$ is equal for all value groups', cannot be rejected ( $95 \%$ significance level).

Next, we carried out the same analysis for each of the six groups of consumption categories of which the energy requirement is based on individual (mainly physical) information from the households, which are: natural gas, electricity, transport, holidays abroad, the dwelling and food (Fig. 4). Also, we made an ANOVA analysis for the sum of those groups. The one-way ANOVA analyses for five of the six groups of consumption categories and the sum of these groups show that the H0-hypothesis, ' $\Delta E$ is equal for all value groups', cannot be rejected $(95 \%$ significance level). Only for dwellings can the H0-hypothesis be rejected. It is assumable that for at least one value group $\Delta E$ for dwellings differs from the others. A closer analysis shows that the Materialists require about $0.7 \mathrm{GJ}$ ( $7 \%$ of the average energy requirement for the dwelling) more energy than average.

\subsection{Energy requirement and problem perception for climate change}

To obtain the consumer's perception of the importance of the environmental problems, we asked the respondents to rank 16 environmental societal problems in order of importance. ${ }^{19} \mathrm{We}$ found that climate change was one of the

\footnotetext{
${ }^{18}$ One-way ANOVA is a one-way analysis of variance for a quantitativedependent variable by a single-factor (independent) variable. Analysis of variance is used to test the hypothesis that several means are equal (van der Bercken and Voeten, 2002).

${ }^{19}$ The 16 environmental societal problems which had to be ranked are: (1) improvement in one's direct living environment, (2) more nature in the Netherlands in future, (3) a better spatial organisation in the Netherlands in future, (4) fewer problems of noise in one's own neighbourhood, (5) no problems in the world of the future caused by the greenhouse effect, (6) no negative influence from genetically modified plants or animals on nature in the world of the future, (7) doing something about over-fertilisation in the
} 


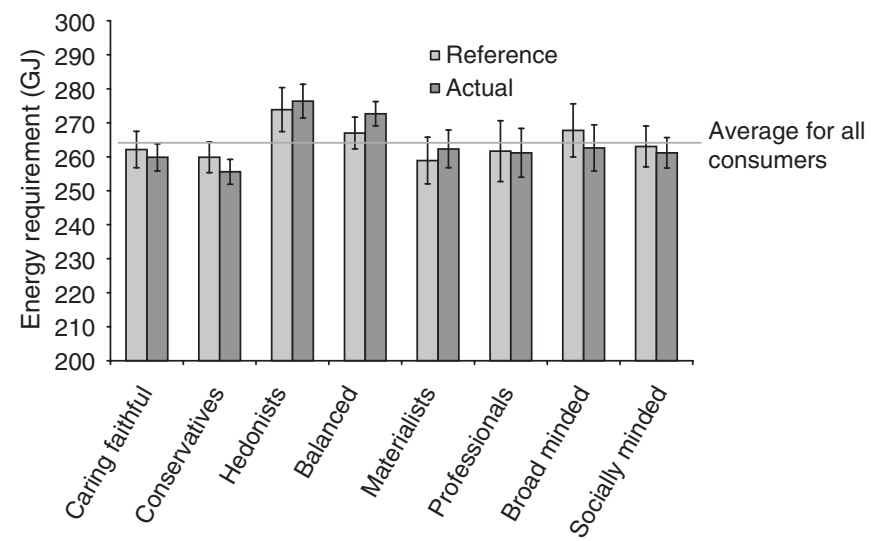

Fig. 2. The total reference energy requirement and total actual energy requirement for the eight value groups, including the standard deviation of the mean. The standard deviation from the mean is calculated by dividing the standard deviation by the square root of $N$ (here $N$ varies between 190 and 497 depending on the value group). This implies that the error intervals in Fig. 2 are equal to a reliability interval of about $67 \%$. Note that the vertical scale does not start at zero.

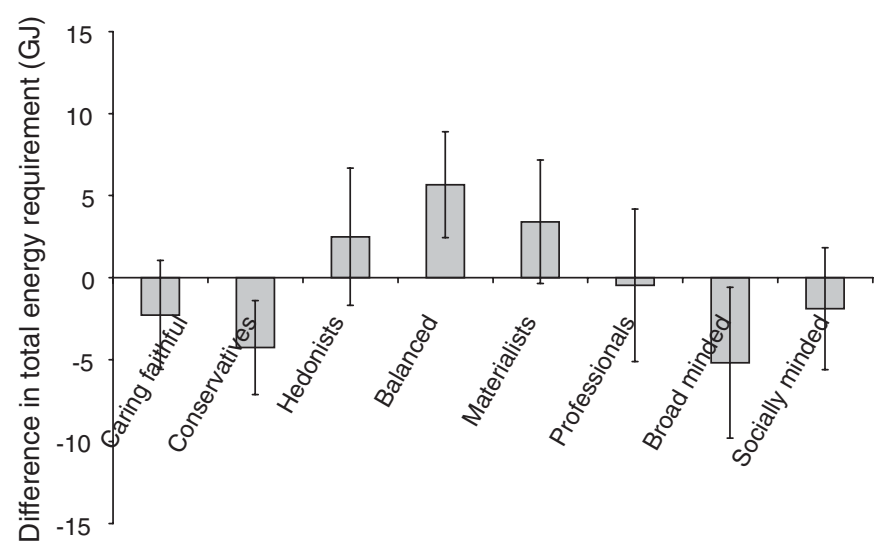

Fig. 3. The difference between total reference and total actual energy requirement $(\Delta E)$ for the eight value groups, including the standard deviation of the mean.

highest ranked environmental problems. We divided the respondents into three groups, one ranking the problem of climate change low (seventh in priority or below), one ranking the problem high (at third place or higher) and one with an average problem perception for climate change (at fourth, fifth or sixth place). Fig. 5 shows the total average energy requirement for the three levels of the perception of the climate change problem.

\section{(footnote continued)}

Netherlands, (8) pre-existence of animals and plants by less deforestation worldwide in the future, (9) a decrease in the pollution of seas, rivers and lakes in the world of the future, (10) a better existence for the animals on Dutch cattle farms, (11) a decrease in air pollution in the Netherlands, (12) taking the environment into account in Dutch consumption, (13) cleaning polluted soil in the Netherlands, (14) raising the quality of public transport in the Netherlands, (15) more clean drinking water for developing countries in future and (16) reduction of the hole in the ozone layer in future. These 16 environmental societal problems were presented randomly to the respondents.
We expect that consumers who ranked the energyrelated problem 'climate change' high would require less energy. The differences between the total reference energy requirement and the total actual energy requirement are small at about $0-2$ GJ $(0-1 \%$ of the total energy requirement). To examine the significance of the differences between the reference energy requirement and actual energy requirement, we calculated, for each respondent, the difference between the actual and reference energy requirement $(\Delta E)$. A one-way ANOVA analysis shows that the H0-hypothesis, ' $\Delta E$ is equal for all problem perception levels', cannot be rejected ( $95 \%$ significance level). We found the same result for the energy requirement of the six groups of consumption categories: natural gas, electricity, transport, holidays abroad, dwelling, food, and the sum of those groups.

\subsection{Energy requirement and the motivation to save energy}

We used data from Kets et al. (2003) to examine the relationship between the energy requirement and the motivation of consumers. The respondents were asked to what extent they were willing to save energy on a 5-point scale, for nine different combinations of costs (higher, the same and less) and comfort (higher, the same and less). Hezemans (2005) made a one-dimensional scale from these nine combinations, which runs from a high willingness to save energy (willing to save energy, even though the costs are higher and the comfort is lower) to a low willingness to save energy (not willing to save energy even though the costs are less and the comfort is higher). We divided the respondents into three groups, one group with the least motivation, one with an average motivation and one with the most motivation to save energy. ${ }^{20}$ Fig. 6 shows the average energy requirement for all three groups.

We expect that consumers highly motivated to save energy would require less energy. The differences between the total reference energy requirement and the total actual energy requirement are about 5-6 GJ (i.e. $2 \%$ of the total energy requirement). To examine the significance of the differences between the reference and actual energy requirement, we calculated the difference between the actual and reference energy requirement for each respondent $(\Delta E)$. A one-way ANOVA analysis shows that the $\mathrm{H} 0$ hypothesis can be rejected. It is assumable that for at least one motivation level group $\Delta E$ differs from the others (95\% significance level). A closer analysis shows that the least motivated group requires about $10 \mathrm{GJ}$ more than the average and most motivated group. Additionally, we made one-way ANOVA analyses for the six groups of consumption categories, electricity, natural gas, transport, holidays

\footnotetext{
${ }^{20}$ Most motivated: $33 \%$ of the respondents with the highest motivation level; least motivated: $33 \%$ of the respondents with the lowest motivation level; average motivated: $33 \%$ of the respondents between the highest and lowest motivation levels.
} 

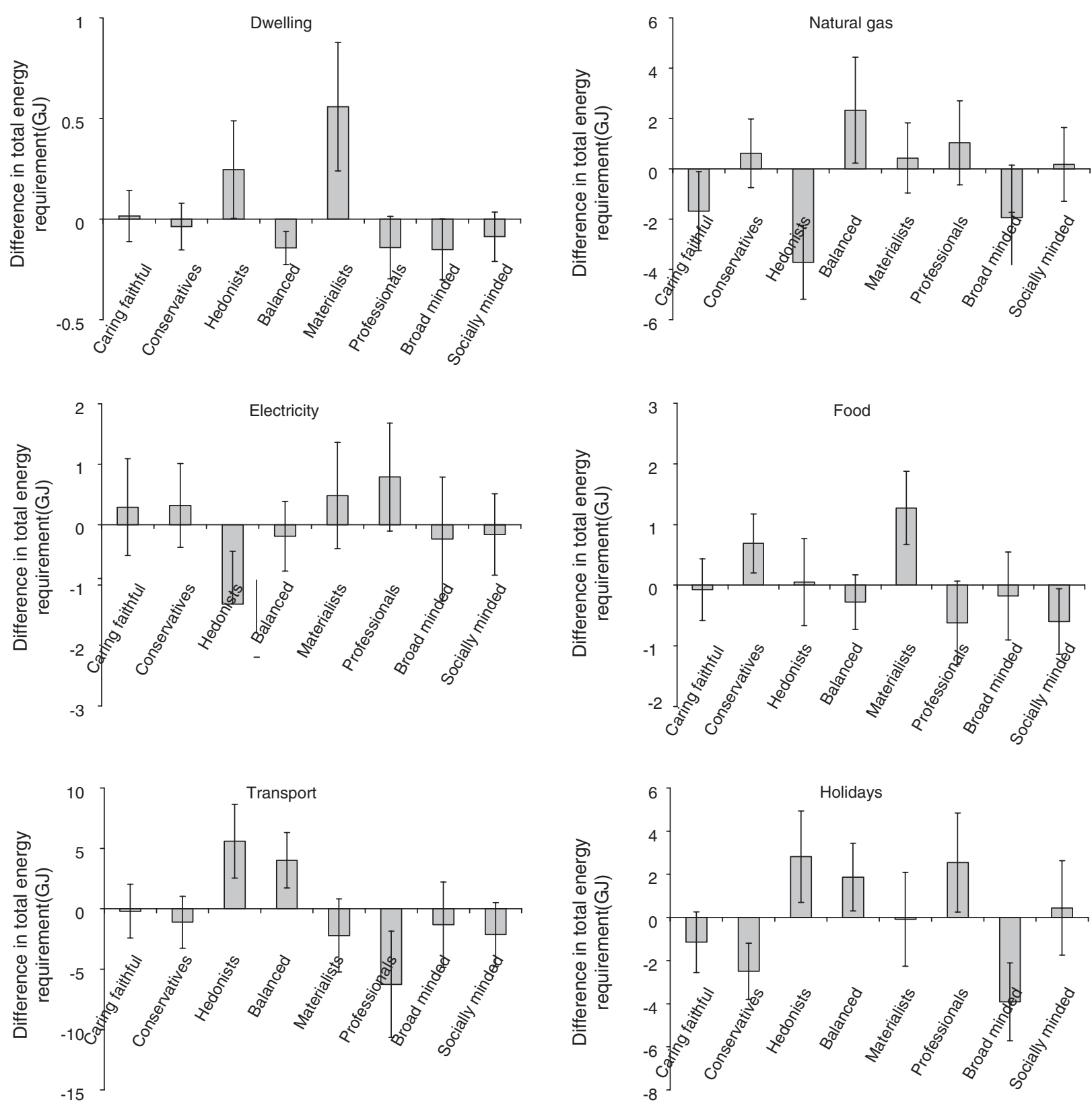

Fig. 4. For all six groups of consumption categories the difference between reference and actual energy requirement $(\Delta E)$ for the eight value groups, including the standard deviation of the mean. Note that the vertical scales differ.

abroad, dwelling, food, and for the sum of those groups. These analyses show that the $\mathrm{H} 0$-hypothesis, ' $\Delta E$ is equal for all motivation levels', cannot be rejected $(95 \%$ significance level). ${ }^{21}$

\subsection{Conclusion}

The one-way ANOVA analyses show that the difference between the actual and reference energy requirement $(\Delta E)$ is

\footnotetext{
${ }^{21}$ This result is consistent with the findings of Hezemans (2005) for electricity.
}

equal for nearly ${ }^{22}$ all groups (95\% significance level), taking into account the differences in the socio-economic situation of the households. The largest significant difference is found between the total energy requirement for the least motivated and average motivated group, which accounts for about $10 \mathrm{GJ}$ or $4 \%$ of the total energy requirement.

\footnotetext{
${ }^{22}$ There are two exceptions: (1) for the value group 'Materialists' is the energy requirement for dwellings about $0.7 \mathrm{GJ}(7 \%)$ higher than expected (according to the socio-demographic situation). (2) For the total energy requirement, the least motivated group requires about $10 \mathrm{GJ}(4 \%)$ more than the average and most motivated groups.
} 


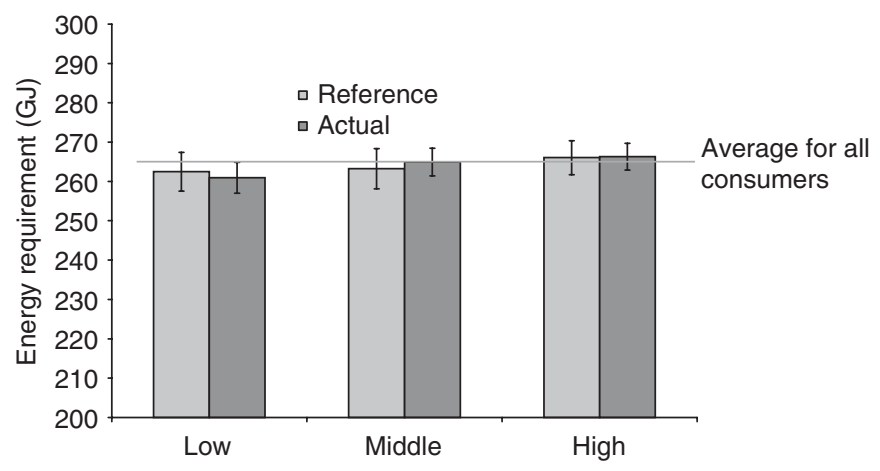

Fig. 5. The total reference and total actual energy requirement for all three problem perception levels for climate change, including the standard deviation of the mean. $N=402$ for the low, 344 for the middle and 526 for the high problem perception level group.

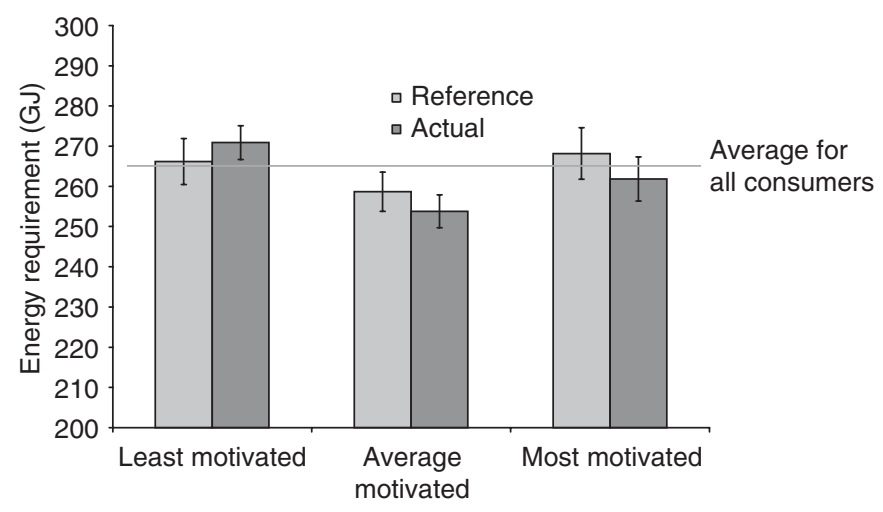

Fig. 6. The total reference and total actual energy requirement for three different levels of motivation for saving energy, including the standard deviation of the mean. $N=$ about 310 for all the three groups.

\section{Low- and high-energy households}

As we have only found relatively small differences in the energy requirement that can be related to values, the perception of the societal problem of climate change or the motivation to save energy, there is still a large part of the variance in the total household energy requirement unexplained. To examine this unexplained variance here, we compare groups of households with either an extremely low or extremely high total household energy requirement. To define high- and low-energy households, we first calculated the difference in energy requirement between the actual and the reference energy requirement. For each income-decile we defined a high-energy group (the $25 \%$ of the households with the highest actual energy requirement, compared with their reference energy requirement) and a low-energy group (the $25 \%$ of the households with the lowest energy requirement, compared with their reference energy requirement). We examined the differences between the low- and high-energy households, relating to the societal problem of climate change and the motivation of these households to save energy. As the net income is by far the most important parameter, we made the analyses for two income groups. ${ }^{23}$ The average socio-economic situation does not differ within the same income group. We found only a small difference ${ }^{24}$ in the urbanisation level; the low-energy households live in a less urbanised area than the high-energy households.

Fig. 7 shows the expenditures and energy requirement for low- and high-energy households, and for low- and high-income groups. The high-energy households require $50 \%$ (high-income) to $100 \%$ (low-income) more energy than the low-energy households, while the expenditure is only about $4 \%$ higher for the high-energy households.

The high-energy households require two (high-income) to four times (low-income) more energy for transport than the low-energy households. ${ }^{25}$ The low-income high-energy households more often have a car, while the high-income high-energy households more often have a second car. The high-energy households drive two (high-income) to four times (low-income) more kilometres and use the car more for commuting between home and work. The distance between home and work is about twice as large for the high-energy households as for the low-energy households. Besides commuting between home and work, the highenergy groups also use the car more for daytrips or nights out. More frequently, they motivate their use of the car as being more comfortable or mention a lack of alternatives in which costs are less important.

For holidays abroad the high-energy households require two (high-income) to three times (low-income) more energy. The high-energy households travelled about four times more than the low-energy ones. High-energy households require twice the energy of low-energy households for accommodation, while their expenditure on this is $50 \%$ lower. Mobile home ownership is higher for the highenergy households.

The high-energy households require 10\% (high-income) to $20 \%$ (low-income) more energy for the dwelling. The high-energy households more often own a dwelling which is relatively older, more often (semi-)detached and 10-15\% larger.

High-energy households require $70 \%$ more energy for natural gas and electricity than low-energy households. They also have about $10 \%$ more kinds of electrical equipment and more energy-intensive equipment like electrical driers and dishwashers. No differences are found between the low- and high-energy households for the possession of energy-saving light bulbs (compact fluorescent lamps) and the purchase of 'green electricity'. However, most of the households, who report buying

\footnotetext{
${ }^{23} \mathrm{We}$ defined the low-income group as the $30 \%$ of households with the lowest net household income and the high-income group as the $30 \%$ of households with the highest net household income.

${ }^{24}$ The urbanisation level differs about 0.5 level on a 5 -level scale. This is equal to the difference between a strong and moderate level of urbanisation.

${ }^{25}$ Remember that doubling the energy requirement for high-income households results in a higher energy requirement than quadrupling the energy requirement for the low-energy households.
} 

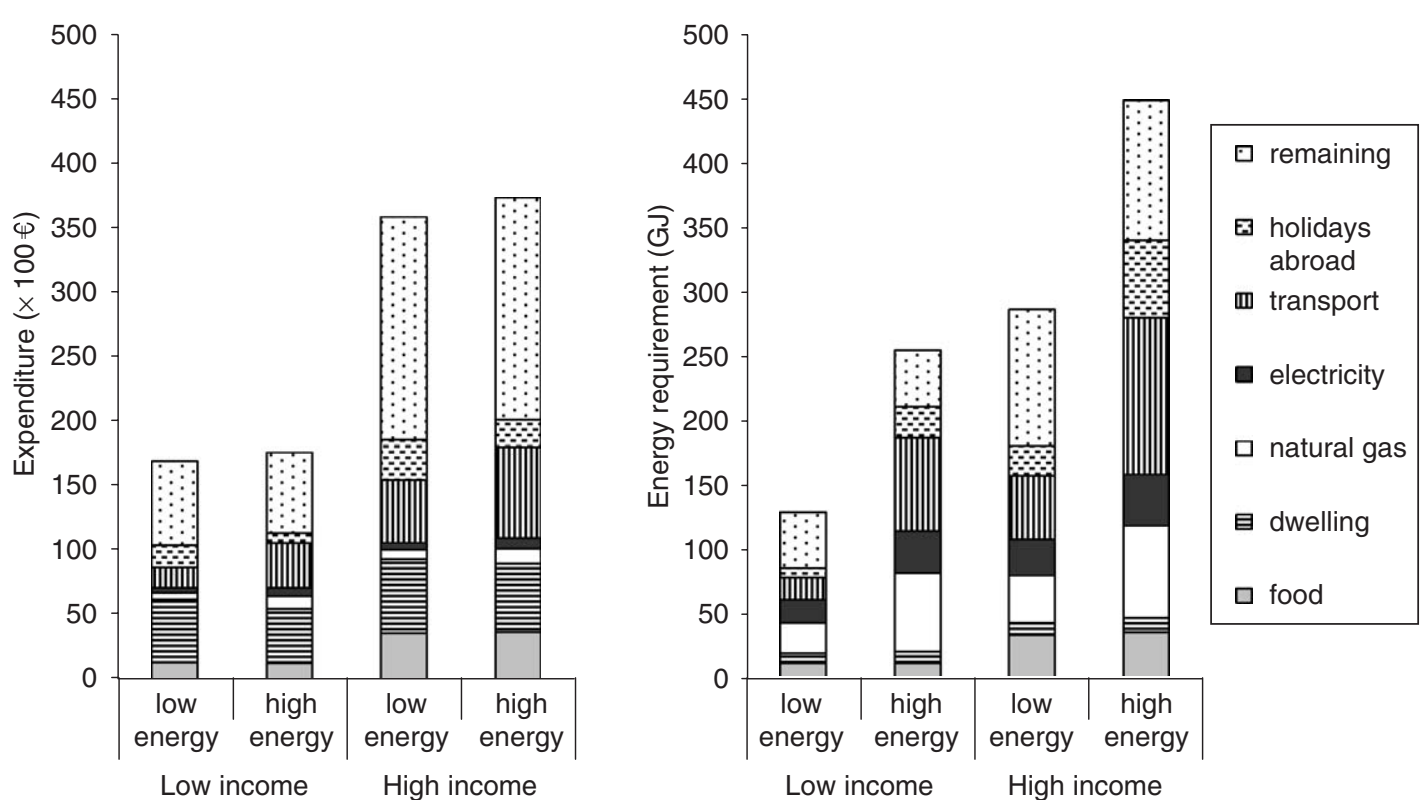

Fig. 7. Expenditures and energy requirement for low- and high-energy and for low- and high-income households.

green electricity, motivate their choice with arguments that green electricity helps to diminish the greenhouse effect $(60 \%)$ and benefits the environment $(75 \%)$. This means that they are aware of the consequences of using energy.

In comparison with the low-energy households, the highenergy households do not require more energy for food.

The comparison of the low-energy households with the high-energy households did not result in significant differences in the order of importance of the two lists of the 18 values, nor the problem perception of climate change. The motivation to save energy differed slightly. We found a difference of 0.7 on a scale from 9 to 45 (see Hezemans, 2005). This difference is not significant $(p=0.05)$. However, if this difference was significant and if motivation plays a role in saving energy, we expected a much larger difference for households using such a different amount of energy.

\section{Discussion}

We first discuss some of the aspects arising from the consumer survey and the calculated household energy requirement. This is followed by a discussion of the results.

\subsection{The consumer survey}

- Studies where the relationship between behaviour, on the one hand, and values, motivation, etc. on the other, are examined with the help of surveys. Socially acceptable answers may introduce a bias in the results. Social acceptability can play a role where respondents are ashamed to give an answer that is not socially acceptable. This effect is avoided as much as possible to guarantee anonymity to the respondents; besides they were allowed to fill in the questionnaires at home, without the presence of an interviewer. Furthermore, our questions were also divided over five separate questionnaires and the respondents did not know that the five questionnaires would be combined later on. The time between two questionnaires varied from two weeks to several months. It was impossible for the respondents to deduct our final research questions, which played the greatest role in the two questionnaires on consumption pattern. The absence of any relation between values, problem perception, motivation and total energy requirement (the actual behaviour) underlined that socially acceptable answers do not play any role in this study.

- The consumer survey contains only data from the breadwinner or her/his partner, while the consumption pattern concerns the whole household, where more persons can be active. In presenting the results, we implicitly assume that the value pattern, the problem perception of environmental problems and the motivation of the breadwinner or her/his the partner to save energy were comparable with the other household members. However, there is one group available in the dataset where this problem did not occur: the oneperson households. For the one-person households, we found results which are comparable with those for the whole population.

\subsection{The calculated energy requirement}

- To calculate the reference energy requirements we used a stepwise linear regression analysis. However, for some groups of consumption categories, the explained variance in the energy requirement is fairly small. 
An alternative reference for the energy requirement might give other results than obtained to date. In our additional analysis, where the standard consumption pattern based on comparable households was chosen as an alternative reference, ${ }^{26}$ the results of the additional analyses with the alternative references were comparable with the results we found earlier. This happened regardless of the number of similar households $(5,10$, 25 or 50 ) we used to calculate this reference.

- In calculating the actual total household energy requirement about $75 \%$ of the total energy requirement is based on individual information on consumption of the respondents. The remaining $25 \%$ of the energy requirement is estimated. The remaining consumption categories are based on the average expenditure and energy requirement from the 10 most similar households taken from the household expenditure survey. Because we do not know whether the values, problem perception and motivation to save energy are equally distributed over these 10 households, we cannot draw any conclusions about a possible relation between the energy requirement due to the remaining consumption categories, on the one hand, and the value patterns, the motivation to save energy or the perception of the societal problem of climate change, on the other.

\subsection{Results}

- In their survey, based on just a few questions, Gatersleben et al. (2002) estimated the energy requirement of their respondent households. They also measured the level of pro-environmental behaviour of the respondents. Our results, based on a much more precise estimation of the household energy requirement, are in line with those of Gatersleben et al. (2002), who found that respondents indicating a more pro-environmental behaviour do not necessarily have a lower total energy requirement. Also, Hezemans (2005) did not find any relationship between value patterns, the motivation to save energy and the use of electricity. Stokes et al. (2004) found that only a small percentage of people who wish to reduce their $\mathrm{CO}_{2}$ emissions are really prepared or able to reduce their actual $\mathrm{CO}_{2}$ emissions. The absence, or at most the presence of a weak relationship between values, problem perception, motivation and total energy requirement can be explained by the presence of a social dilemma. Antonides and van Raaij (1997) mention the conflict between thinking in an environmental way and not doing so, due to a conflict between short-term individual interests and collective long-term interests. In the response to the consumer survey, we observed that

\footnotetext{
${ }^{26}$ Disadvantage of taking the estimated consumption pattern as reference is that the estimated consumption pattern is based on only a few (5-50) similar households. We do not know whether all value patterns, levels of problem perception and levels of the motivation to save energy are equally distributed over the similar households.
}

most of the respondents thought that not they, themselves, but others (with an emphasis on the public authorities), should come up with the solution to the most important societal problems, thus supporting the existence of a social dilemma. We also found that both the low- and the high-energy households from the consumer survey think that a climate policy should best be started without further delay. More research will be required to find out why people do not consume according to their values, problem perception or motivation to save energy. However, this does not answer the question on why comparable households differ so much on their consumption patterns, with a large difference in total energy requirement as result.

\section{Conclusions}

Households in the same socio-economic situation can differ largely in their total energy requirement. Despite a detailed calculation of the energy requirement of individual consumption patterns we could not find that the energy requirements of one of the groups examined for value patterns or problem perception level of climate change significantly differed from the rest, taking into account the differences in the socio-economic situation of households. Only for the motivation to save energy we did find that the difference between the total energy requirement for the least motivated and average motivated group, amounts to about $10 \mathrm{GJ}$; this is about $4 \%$ of the total energy requirement.

We can conclude that the lack of a relation between the total household energy requirement and value patterns of consumers or their problem perception of climate change or their motivation to save energy, will mean that a selfregulating energy policy, solely based on a strategy of internalising environmental responsibility, will not be effective in saving energy. There are indications that the social dilemma is one of the reasons why people do not consume according to their value patterns, problem perception or motivation to save energy.

\section{Acknowledgements}

We would like to thank Harm Jeeninga and Anne Kets from the Netherlands Energy Research Foundation (ECN) for the use of the data on the motivation scale, and also Ellen Hessing-Couvret (TNS-NIPO), Albert Reuling (Reuling research) and Dieter Verhue (Veldkamp) for their help with the fieldwork for the survey and the interpretation of the value groups. Our thanks goes out to Anne Hezemans for developing a scale for measuring the motivation to save energy, and finally to Durk Nijdam, Eric Drissen, Hans Visser and Sebina Rosbergen (all from the Netherlands Environmental Assessment Agency (MNP)) for their help with the calculation and estimation of the consumption pattern. 


\section{References}

Aalbers, L., 2004. Personal communication. Carlson Wagonlit travel, Diemen, d.d. 30 September 2004.

ANWB, 2003. Internet site 〈www.anwb.nl〉, September 2003.

Antonides, G., van Raaij, W.F., 1997. Consumentengedrag, een sociaalwetenschappelijke benadering (Consumer behaviour, a social-scientist approach). Uitgeverij Lemna B.V., Utrecht.

Belastingdienst, 2003. Internet site 〈www.belastingdienst.nl〉, September 2003.

van der Bercken, J.H.L., Voeten, M.J.M., 2002. Variantieanalyse, De GLM benadering. Stenfert Kroese, Groningen.

Biesiot, W., Noorman, K.J., 1999. Energy requirements of household consumption: a case study of The Netherlands. Ecological Economics 28 (3), 367-383.

Carlsson-Kanyama, A., Karlsson, R., Moll, H.C., Kok, R., Wadeskog, A., 2002. Household metabolism in the Five Cities. Swedish National Report-Stockholm. Fms report 177, Forskningsgruppen för Miljöstrategiska Studier, Stockholm, Sweden.

CASEMA, 2003. Average of tariffs. Internet site 〈www.casema.nl〉, July 2003.

CBS, 2002a. Budgetonderzoek 2000, micro bestand (Household Expenditure Survey 2000, computer file). Statistics Netherlands, Voorburg/ Heerlen.

CBS, 2002b. Consumenten prijs indexen, Statline (Consumer price indexes, Statline). Statistics Netherlands, Voorburg/Heerlen.

CBS, 2003. Statline, Internet site: 〈www.cbs.nl〉, Statistics Netherlands

Cohen, C.A.M.J., Lenzen, M., Schaeffer, R., 2005. Energy requirements of households in Brazil. Energy Policy 33, 555-562.

Consumentenbond, 2003. Consumentengids (Consumer guide), August 2003.

Erkens, 2002. Personal communication. Statistics Netherlands, Voorburg/ Heerlen, d.d. 11 March 2002.

Essen, H. van, Bello, O., Dings, J., van den Brink, R., 2003. To shift or not to shift, that's the question, the environmental performance of the principal modes of freight and passenger transport in the policymaking context. CE and RIVM, Delft.

Gatersleben, B., Steg, L., Vlek, Ch., 2002. Measurement and determinants of environmental significant consumer behaviour. Environment and Behaviour 34 (3), 335-362.

GVU, 2003. Internet site of the local transport company. 〈www.gvu.nl〉, August 2003.

Hessing-Couvret, E., Reuling, A., 2002. Het WIN-model, waardensegmenten in Nederland (The WIN-model, value systems in the Netherlands). TNS-NIPO, Amsterdam.

Hezemans, A., 2005. Tussen denken en doen, de samenhang tussen elektriciteitsverbruik, normen en warden, vernieuwingsdrift en motivatie om energie te besparen (Between thought and action, the relationship between the use of electricity, values, innovation and motivation to save energy. Student Thesis, Utrecht University, Utrecht.

IPCC, 2001. Intergovernmental Panel on Climate Change (IPCC), Climate change 2001, Mitigation. Third Assessment Report, Intergovernmental Panel on Climate Change.

Kets, A., van Arkel, W., Jeeninga, H., 2003. Energiebesparing en huishoudens-Een onderzoek naar energiebesparing, typen huishoudens, geprefereerde doelstellingen en motivatie (Energy saving and households - a study on energy saving, types of households, preferred targets and motivation). Netherlands Energy Research Foundation (ECN) Petten.

Kok, R., Benders, R.M.J., Moll, H.C., 2001. Energie-intensiteiten van de Nederlandse consumptieve bestedingen anno 1996. Report No. 105, Centre for Energy and Environmental Studies (IVEM), University of Groningen (RUG), Groningen.

Lenzen, M., 1998. Primary energy and greenhouse gases embodied in Australian final consumption: an input-output analysis. Energy Policy 26 (6), 495-506.
Lenzen, M., Dey, C., Foran, B., 2004. Energy requirements of Sydney households. Ecological Economics 49 (3), 375-399.

Lenzen, M., Wier, M., Cohen, C., Hayami, H., Pachauri, S., Schaeffer, R., 2006. A comparative multivariate analysis of household energy requirements in Australia, Brazil, Denmark, India and Japan. Energy 31, 181-207.

van Maanen, J., 2003. Gemiddelde energietarieven 2003 (Average energy rates 2003). Personal communication, EnergieNed, Arnhem.

MONIT, 2003. Monitoring Ontwikkeling Nationaal verbruik, Informatie en Trendanalyse (Monitoring the development of national energy use, information and trend analysis). Netherlands Energy Research Foundation (ECN), Petten.

Munksgaard, J., Pedersen, K.A., Wier, M., 2000. Impact of household consumption on $\mathrm{CO}_{2}$ emissions. Energy Economics 22, 423-440.

Nordlund, A.M., Garvill, J., 2002. Value structures behind pro-environmental behaviour. Environment and Behaviour 34, $740-756$.

NS, 2003. Internet site 〈www.ns.nl〉 of the Dutch Railway Company.

de Paauw, K.F.B., 1995. Energieaspecten van vrije-tijdbesteding, verzorging, communicatie en roken. Een mogelijke energiereductie bij huishoudens (Energy aspects of leisure, care, communication and smoking. A possible energy reduction by households). Report No. ECN-C-95-026, Netherlands Energy Research Foundation (ECN), Petten.

Pachauri, S., 2004. An analysis of cross-sectional variations in total household energy requirements in India using micro survey data. Energy Policy 32 (15), 1723-1735.

Pachauri, S., Spreng, D., 2002. Direct and indirect energy requirements of households in India. Energy Policy 30, 511-523.

Poortinga, W., Steg, L., Vlek, Ch., 2004. Values, environmental concern and environmental behaviour, a study into household energy use. Environment and Behaviour 36 (1), 70-93.

Rokeach, M., 1973. The Nature of Human Values. The Free Press, New York.

Schwartz, S.H., Bilsky, W., 1987. Toward a universal psychological structure of human values. Journal of Personality \& Social Psychology $53(3), 550-562$.

Sierman, C.J.L., 2003. Personal communication. Statistics Netherlands, Voorburg/Heerlen, d.d. 26-8-2003.

Steg, L., Buijs, A., 2004. Psychologie en duurzame ontwikkeling. Vakreview, UCM-KUN.

Stokes, D., Lindsay, A., Marinopoulos, J., Treloar, A., Wescott, G., 1994. Household carbon dioxide production in relation to the greenhouse effect. Journal of Environmental Management 40, $197-211$.

The Economist, 2004. Internet site: 〈www.economist.com〉, November 2004.

TNS-NIPO, 2003. Computerfile of the consumer survey. TNS-NIPO, Amsterdam.

Valette-Florence, P., Jolibert, A., 1990. Social Values, A.I.O., and Consumption patterns, exploratory findings. Journal of Business Research 20, 109-122.

Vringer, K., Blok, K., 1993. Energie-intensiteiten van de nederlandse woning (The energy intensities of Dutch houses. Report No. 93037, Department of Science, Technology and Society (NW\&S), Utrecht University (UU), Utrecht.

Vringer, K., Blok, K., 1995. The direct and indirect energy requirement of households in the Netherlands. Energy policy 23 (10), 893-910.

Vringer, K., Gerlagh, T., Blok, K., 1997. Het directe en indirecte energiebeslag van Nederlandse huishoudens in 1995 en een vergelijking met huishoudens in 1990 (The direct and indirect energy requirement of Dutch households in 1995 and a comparison with 1990). Report No. 97071, Department of Science, Technology and Society (NW\&S), Utrecht University (UU), Utrecht.

Vringer K., Aalbers, Th.G., Drissen, E., Hoevenagel, R., Bertens, C.A.W., Rood, G.A., Ros, J.P.M., Annema, J.A., 2001. Nederlandse 
consumptie en energiegebruik in 2030. Een verkenning op basis van twee lange termijn scenario's (Consumption and energy requirement for Dutch consumers in 2030. A survey based on two long-term scenarios). National Institute of Public Health and Environment, Bilthoven.

Weber, C., Perrels, A., 2000. Modelling lifestyle effects on energy demand and related emissions. Energy Policy 28 (8), 549-566.
Wier, M., Lenzen, M., Munksgaard, J., Smed, S., 2001. Environmental effects of household consumption pattern and lifestyle. Economic Systems Research 13 (3), 259-274.

Wilting, H.C., Benders, R.M.J., Biesiot, W., Lourerd, M., Moll, H.C., 1999. EAP, Energy Analysis Program, Manual version 3.0. Report No. 98, Centre for Energy and Environmental Studies (IVEM), University of Groningen (RUG), Groningen. 